\title{
Critical assessment of a refractory metal dissolution experiment in inductive cold crucible
}

\author{
F. REVET, C. MÉNNÉTRIER ${ }^{*}$ and F. DURAND ${ }^{* *}$ \\ CEZUS, détachée au Laboratoire MADYLAM \\ * CEZUS, Centre de Recherches, 4 avenue Paul Girod, 73400 Ugine, France \\ ** Laboratoire MADYLAM, ENSHMG, BP. 95, 38402 Saint Martin d'Hères cedex, France
}

\begin{abstract}
An academic study of the dissolution kinetics of niobium in a titanium melt is presented. A series of experiments was performed, using an inductive cold crucible melting furnace. The experimental samples, small rods of niobium and billets of titanium, are submitted to geometrical and chemical characterization. In the paper, experimental dissolution results are presented and are expressed in the form of a mass transfer coefficient.
\end{abstract}

\section{I - Introduction}

The elaboration of refractory alloys usually involves a liquid phase step in which addition elements are dissolved and homogenized. According to Ohno [1], many papers are devoted to experimental studies of dissolution in several systems of low temperature alloys. However, the dissolution of a refractory metal in a metallic melt hasn't been extensively discussed. Mitchell [2], studied the kinetics of dissolution of niobium in a titanium melt, using an electron beam melting process. From a technical point of view, the Ti-Nb system is very interesting (superconducting alloys), but there are problems in the elaboration with the VAR process [3]. More, the corresponding solid-liquid equilibria involve a continuous series of solid solutions, which means no intermetallic phases. However, the liquidus isn't well determined, and this can be a source of problems.

We have chosen to study that 'Ti-Nb system, but using an inductive cold crucible melting process, which is known as a clean melting process, suitable for reactive or refractory alloys elaboration. Compared to the currently used processes (ie EBCHR and VAR), the inductive cold crucible operates under a protective argon atmosphere which limits vaporization losses.

The long range objective is to predict the production rate of $\mathrm{Ti}-\mathrm{Nb}$ alloys as a function of the process parameters. In the paper, we present experimental dissolution results, and we express them in the form of a mass transfer coefficient.

\section{II - Experimental device and procedure}

The experimental device has previously been presented [4]. The liquid metal is obtained by melting the upper part of a billet of pure titanium ( $5 \mathrm{~cm}$ in diameter). Melting is performed by medium frequency induction in a cylindrical watercooled segmented copper crucible. In our conditions, the induced currents are concentrated in the electromagnetic skin of the metallic charge, which is approximately $3 \mathrm{~mm}$ thick. These currents have complex effects. The charge is heated by Joule effect, the heating is direct, rapid, and without contact. The electromagnetic forces create an intense and turbulent stirring into the liquid part of the sample. This stirring speeds up heat and mass transfer controlling elaboration kinetics. Moreover, these forces have a repulsion effect, which limits the contact between the charge and the watercooled crucible. The repulsion is of high importance because it contributes in reducing heat losses.

The dissolving sample is a rod of pure niobium, $10 \mathrm{~mm}$ in diameter. A specimen holder mecanism allows a 
vertical translatory movement, a rotation and an off-centering of the rod. At the beginning of an experiment, the rod is brought close to the liquid surface for a ten minutes preheating. Then it is dipped into the bath, with or without rotation. Once the immersion time is over, the sample is removed and the power is gradually turned off.

After the experiment, the dissolved sample has a complex shape (Fig.1.a). Some melt has solidified in contact with the rod, forming a flange which is taken off mechanically The solid rod is weighed and its total length and diameter are measured and compared with initial values. This gives the decrease in diameter and the mass-loss. The billet is cut longitudinally. On one half, a macrography reveals the shape of the molten pool (Fig.2.b), from which the melt volume is estimated. On the second part, the increase in solute content is determined by chemical analysis, giving a second estimate of the amount of dissolved niobium.

\section{III - Model for exploiting the experimental results (Symbols are listed at the end of the paper)}

During an experiment, the solid-liquid area changes, the melt composition increases. Then, the backward velocity of the dissolving interface is not a constant. In order to analyse the experimental results, taking into account the existing phenomena, a model has been built. It allows the calculation of an experimental mass transfer coefficient which is the only variable allowing comparisons between experiments.

The melting temperature of the solid addition $\left(2468^{\circ} \mathrm{C}\right)$ is much higher than the bath temperature $\left(\approx 1700^{\circ} \mathrm{C}\right)$, and then the mass transfer is the limiting process for the dissolution period [5]. We assume a convective mass transfer with a diffusion boundary layer.

The considered system is made of two phases : a solid phase $S$, which is the addition and a liquid phase $L$, which is the melt. Each phase is composed of two species, A and B. B is the major component in the solid. In the liquid, it is the minor component, it will be called solute. The compositions of the phases are expressed in atom fractions, $X$. They vary with time and distance from the solid-liquid interface.

We are considering a closed system which is described by $\mathrm{n}$, total number of moles, $\mathrm{g}$, molar fraction of solid in the whole system and ( $1-\mathrm{g})$, molar fraction of liquid in the whole system. In the transformation $\left(\mathrm{g} \rightarrow \mathrm{g}-\mathrm{dg}\right.$ ) between the initial and the final state, $\mathrm{dn}_{\mathrm{B}}$, the number of moles of $\mathrm{B}$ which are transferred from the solid to the bulk in order to modify its concentration, can be expressed by equation 1 .

$$
d n_{B}=n \cdot d g \cdot\left(X_{B}^{s}-X_{B}^{L}\right)
$$

The dissolution kinetics involves mass flow rates, $\mathrm{J}$, in the solid and in the liquid. We can limit the study to the solute transfer. As the bath is strongly stirred three assumptions can be made : 1) the melt is perfectly mixed, 2) the concentration gradient exists only in the liquid boundary layer, and 3) there is no solute storage in this latter. In the solid, there may be a diffusion layer with a gradient, but with a very small thickness, then the non storage assumption is made. So we can link $J_{B}^{L}$ with the number of moles $\mathrm{dn}_{B}$ which are transferred during time dt for an interface element dS.

$$
\mathrm{dn}_{\mathrm{B}}=\mathrm{dS} . \mathrm{dt} . \mathrm{J}_{\mathrm{B}}^{\mathrm{L}}
$$

$J_{B}^{L}$ can be expressed with a convective mass transfer coefficient, $k_{B}$ which is a function of the point $M$, the temperature at $\mathrm{M}$, and the convective state of the bath near $\mathrm{M}$.

$$
J_{B}^{L}=k_{B} \cdot\left(C_{B}^{L^{*}}-C_{B}^{L}\right)
$$

with $\mathrm{C}_{\mathrm{B}}^{\mathrm{L}^{*}}=\mathrm{X}_{\mathrm{B}}^{\mathrm{L}^{*}} / \mathrm{V}^{\mathrm{L}^{*}}$ and $\mathrm{C}_{\mathrm{B}}^{\mathrm{L}}=\mathrm{X}_{\mathrm{B}}^{\mathrm{L}} / \mathrm{V}^{\mathrm{L}}$

During the transformation ( $\mathrm{g} \rightarrow \mathrm{g}-\mathrm{dg}$ ), the considered element of interface is submitted to a movement (-dy) along its external normal. We have chosen a referential linked to the bulk of the solid. Because of the non storage assumption, the diffusion boundary layer has no influence on the displacement of the interface, which is given by equation 4 .

$$
-V^{S} \cdot n \cdot d g=-d S \cdot d y
$$


The solute mass balance is :

$$
\mathrm{n} \cdot \mathrm{dg} \cdot\left(\mathrm{X}_{\mathrm{B}}^{\mathrm{S}}-\mathrm{X}_{\mathrm{B}}^{\mathrm{L}}\right)=\mathrm{dS} \cdot \mathrm{dt} \cdot \mathrm{J}_{\mathrm{B}}^{\mathrm{L}}
$$

The backward movement velocity of the dissolving interface can then be obtained :

$$
\frac{d y}{d t}=\frac{V^{S} \cdot k_{B}}{X_{B}^{S}-X_{B}^{L}}\left(\frac{X_{B}^{L^{*}}}{V^{L^{*}}}-\frac{X_{B}^{L}}{V^{L}}\right)
$$

$\mathrm{k}_{\mathrm{B}}$, expressed via equation 6 , is used to analyse the experimental results. In this treatment supplementary assumptions are made :

$-\mathrm{V}^{\mathrm{L} *}=\mathrm{V}^{\mathrm{L}}$

- the interfacial temperature is uniform all along the interface, and is a constant during the experiment.

- the dissolving sample keeps a cylindrical shape all along the experiment.

Then $\mathrm{k}_{\mathrm{B}}$ is independent of point $\mathrm{M}$, and the displacement velocity of the interface is uniform. Radius and length of the rod decrease identically. Equation (6) becomes :

$$
k_{B}=\left(\frac{V^{L}}{V^{S} \cdot d t}\right) \cdot\left(d y \cdot \frac{X_{B}^{S}-X_{B}^{L}}{X_{B}^{L^{*}}-X_{B}^{L}}\right)
$$

Equation (7) allows the calculation of $\mathrm{k}_{\mathrm{B}}$ at a given instant, from an instantaneous (dy/dt). Unfortunately, we only have initial and final data. To get $k_{B}$, an integration is performed step by step numerically, from the initial radius to the final one :

$$
k_{B}^{\exp _{B}}=\frac{V^{L}}{V^{s}} \cdot \frac{1}{t_{i m}} \cdot \int_{r_{O}}^{r_{f}} \frac{X_{B}^{s}-X_{B}^{L}(r)}{X_{B}^{L^{*}}-X_{B}^{L}(r)} d r
$$

Consequently, $\mathrm{k}_{\mathrm{B}}^{\mathrm{ex}}$ is a mean value with respect to time and space.

\section{IV - Discussion}

In our experiment, there are many parameters which cover a large variation range : the immersion time $(60$ to $1800 \mathrm{~s})$, the frequency $(10$ to $50 \mathrm{kHz})$, the immersed length $(1$ to $6 \mathrm{~cm})$, the rotation speed $(0$ to 1000 $\mathrm{rpm}$ ) and the power input in the metallic charge ( 3 to $7 \mathrm{~kW}$ ).

Data also cover a large variation range : $\mathrm{m}$, mass loss $(1$ to $30 \mathrm{~g})$, Wb, final weight percent of $\mathrm{B}$ in the melt $(0.5$ to $14 \%)$, and $\mathrm{Vb}$, volume of the metallic melt $\left(30\right.$ to $\left.90 \mathrm{~cm}^{3}\right)$.

For each experiment, two calculations of $n_{f}$, the final number of moles of $B$ in the liquid phase, are made, one with the mass loss results (m.), and another one with the final melt concentration obtained by analysis (an.).

$$
\begin{aligned}
& \mathrm{n}_{\mathrm{f}}(\mathrm{m} .)=\frac{m}{M_{B}} \\
& \mathrm{n}_{\mathrm{f}}(\mathrm{an} .)=\frac{V_{b}}{V_{A}^{L}} \cdot \frac{X_{f B}^{L}}{1-X_{f B}^{I}}
\end{aligned}
$$

with :

$$
X_{f B}^{L}=\frac{W b}{M_{B}}\left(\frac{W b}{M_{B}}+\frac{100-W b}{M_{A}}\right)^{-1}
$$

Then there are two data sources that can be compared. Figure 2 represents $n_{f}\left(a n\right.$.) as a function of $n_{f}(m$.), assuming $\mathrm{a} \pm 0.2 \mathrm{~g}$ error on $\mathrm{m}$ and $\pm 15 \%$ error on $\mathrm{Vb}$. Only a few points are distant from the first diagonal 
line, which means that the two values are consistent and the experimental procedure is satisfactory when considered by itself.

Nevertheless, the presented calculation turns on the mass transfer coefficient, $k_{B}^{\text {exp }}$, and not on $n_{f}$. Consequently, we have to study the error spreading during the treatment. Especially, we test the denominator in equation $8,\left(X_{B}^{L^{*}}-X_{B}^{L}(r)\right)$, taken for the final radius $r_{f} . X_{B}^{L^{*}}$ is read on the phase diagram for the experimental temperature, measured with a pyrometer. We assume a very small error of $0.1 \%$ on $X_{B}^{L^{*}}$. There are two ways of achieving $X_{B}^{L}\left(r_{f}\right)$. The first one is the analysis, which gives directly $X_{B}^{L}\left(r_{f}\right)$ via equation 11 . The second way is the mass loss, according to equation 12 :

$$
X_{B}^{L}\left(r_{f}\right)(m .)=\frac{n_{f}(m .)}{n_{f}(m .)+\frac{V b}{M_{A}}}
$$

This expression involves $\mathrm{Vb}$, and then its error is now transferred on $\mathrm{X}_{B}^{\mathrm{L}}\left(\mathrm{r}_{\mathrm{f}}\right)$. Consequently, the results arising from analyses should be more reliable than the results arising from mass loss. More, the error is especially concentrated on the upper limit integration, and the short-lived dissolution experiments are the most tainted with it.

At the moment, the values of $\mathrm{k}_{\mathrm{B}}^{\mathrm{exp}}$ show a large dispersion range, whether the treatment is made via $\mathrm{Vb}$ or via $m$. The mean value is :

$$
\mathrm{k}_{\mathrm{B}}^{\exp }=70 \pm 20 \mu \mathrm{m} \cdot \mathrm{s}^{-1}
$$

Unfortunately, because of this dispersion, no correlation with the experimental parameters can be detected. As an example, we have tested the influence of the immersion duration (Fig. 3). Figure 4 represents $k_{B}^{\exp }$ as a function of $\omega_{\text {rot }}$, the rotation speed of the niobium rod in axial position. The graph shows no correlation even though $\omega_{\text {rot }}$ is increased up to $1000 \mathrm{rpm}$. This means that the turbulent stirring generated by the electromagnetic forces is much stronger than the flow created by the sample movement.

\section{V - Conclusion}

Our dissolution model gives a convective mass transfer coefficient which can be used in predicting further experiments, and particularly in industrial production.

The value of the convective mass transfer coefficient is about $70 \mu \mathrm{m} . \mathrm{s}^{-1}$, which is much higher than the one proposed by Mitchell [2] (13.3 $\left.\mu \mathrm{m} . \mathrm{s}^{-1}\right)$. This is probably resulting from the intense turbulent stirring created in cold crucible, which doesn't exit in electron beam process.

In order to separate the influence of the experimental parameters, a larger crucible diameter should be used for the experiment.

\section{List of symbols :}

$\mathrm{k}$ : mass transfer coefficient

$\mathrm{X}$ : atomic fraction

$\mathrm{n}:$ number of moles

$\mathrm{g}:$ molar fraction of solid in the whole system

$\mathrm{J}$ : mass flow rate

$\mathrm{dg}, \mathrm{dn}_{\mathrm{B}} . \mathrm{dt}, \mathrm{dr}$ : increment of the considered variables

$\mathrm{dS}$ : interfacial element

C : volumic concentration

$\mathrm{V}:$ molar volume

dy: displacement of interface

$t_{\text {im }}$ : immersion time

$\mathrm{r}$ : rod radius

$\mathrm{m}$ : mass loss

$\mathrm{Wb}$ : final weight percent of $\mathrm{B}$ in the melt

[m.s $\left.\mathrm{s}^{-1}\right]$

[mol.]

[mol.m-2. $\left.\mathrm{s}^{-1}\right]$

[m $\left.\mathrm{m}^{2}\right]$

[mol. $\mathrm{m}^{-3}$ ]

$\left[\mathrm{m}^{3} \cdot \mathrm{mol}^{-1}\right]$

[m]

[s]

[m]

[g] 
$\mathrm{Vb}$ : volume of the liquid

M : molar mass of pure species $\left[\mathrm{m}^{3}\right]$

[g. $\mathrm{mol}^{-1}$ ]

\section{Superscripts :}

$\mathrm{S}, \mathrm{L}$ : solid or liquid phase

$*$ : interfacial value

exp : experimental

\section{Subscripts :}

A, B ; species

0 : initial

$f$ : final

\section{References :}

[1] OHNO R;, Met. Trans. 4 (1973) 909-915

[2] TRIPP D.W., MITCHELL A., preprint (1990)

[3] HILLMAN H., RUDINGER K., HEISTERKAMP F., WAGNER K.P., HULKA M., SIBUM H., J. Metals (1989) 20-22

[4] REVET F., DURAND F., MENNETRIER C., Le vide, les couches minces, 261 (1992) 16-18

[5] KATZ S., Metals Handbook ASM, (1990) 49-81

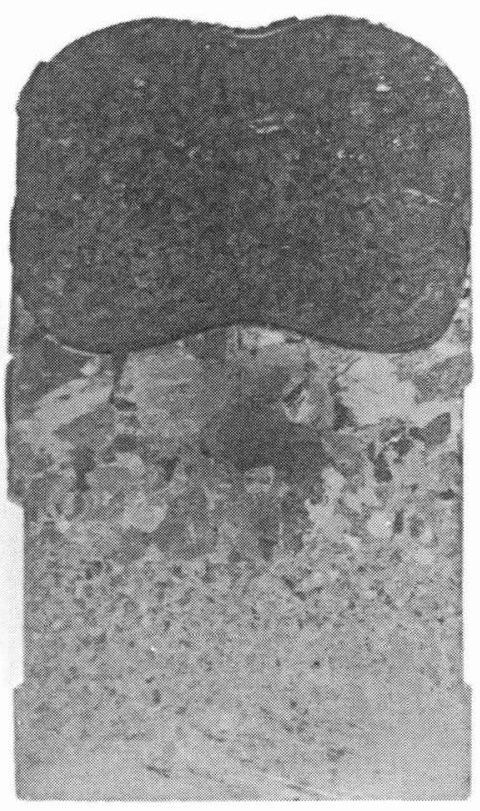

b

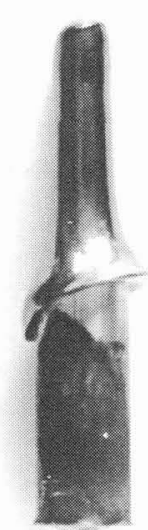

$\mathbf{a}$

Figure 1 : Experimental samples after experiment a : rod of pure niobium

b : macrography of a billet of titanium, the darker part was the melt 


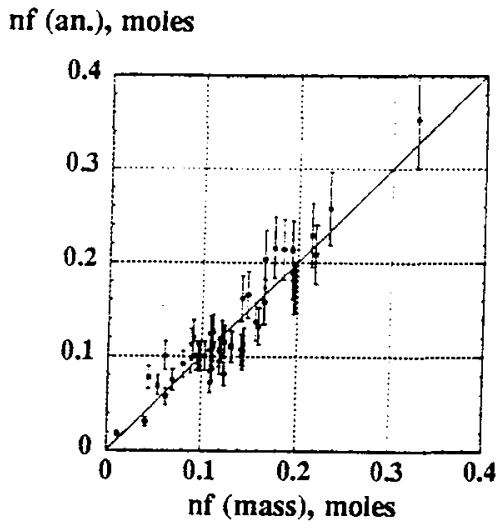

Figure $2: n_{f}$ (analyses) as a function of $n_{f}$ (mass loss)

$\mathrm{k}$, micron . $\mathrm{s}^{-1}$

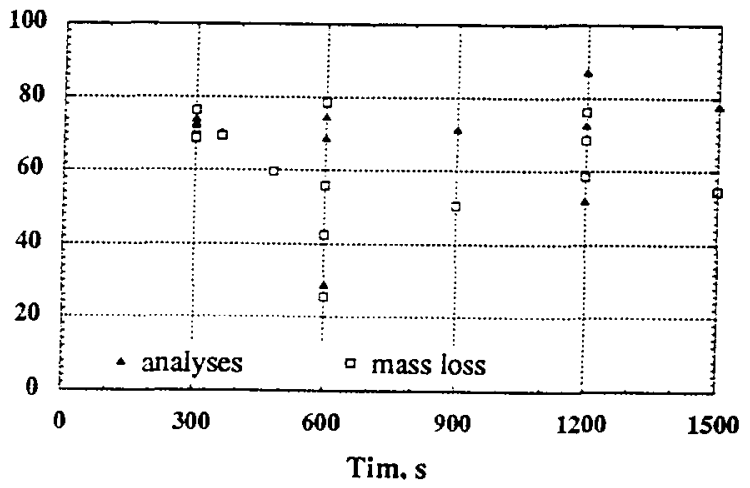

Figure 3 : Mass transfer coefficient, $k_{B}^{\exp }$, as a function of the immersion time, $t_{i m}$

k. micron . $\mathrm{s}^{-1}$

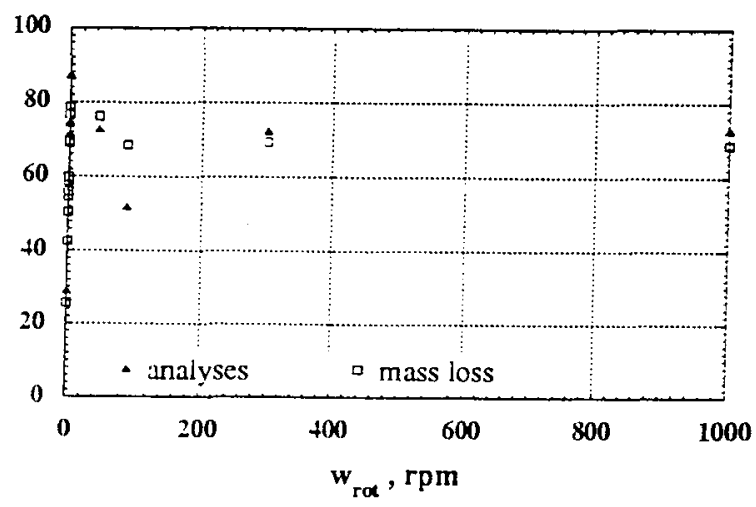

Figure 4 : Mass transfer coefficient, $k_{B}^{\exp }$, as a function of the rotation speed, $\omega_{\text {rot }}$ 